\title{
The study of nutrition value and physico-chemical properties on cross- linked rye noodles
}

\begin{abstract}
Today, one of the biggest challenges in the food industry is the production of cheap food, with, a high nutritional value. Wheat plays an important role in the human diet as one of the most important agricultural products around the world. Noodle is a product rich in carbohydrates without cholesterol, with a low sodium and fat content, but it is very poor in terms of essential amino acids such as lysine and threonine. Noodle has a particular popularity in human societies because of its cost-effectiveness, ease of use and the diversity of its forms. Due to the production stage of this product, additives can easily be added to the noodle formulation, so the newest enrichment in the industry is the use of rye flour, which has been studied in this research. In this study, wheat flour, salt, trans-glutaminase and rye flour were pre-prepared. The level of enzyme transglutaminase was fixed at $1 \%$ and rye flour in $0,20,40$ and $60 \%$ in noodles formulation. Proximate analysis, cooking properties, firmness and tensile were investigated. The results showed, the addition of rye flour at level of $40 \%$, decreased the firmness due to increasing of water uptake and increased the tensile strength of the cross-linked rye noodles because of gluten properties of rye protein. In addition, adding rye flour increased nutrition value of noodles.
\end{abstract}

Volume 8 Issue 2 - 2018

\begin{abstract}
Lida Shahsavani, Fatemeh Hosseinmardi
Department of Food Science and Technology, Islamic Azad University, Iran
\end{abstract}

Correspondence: Lida Shahsavani, Department of Food Science and Technology, Shahr-e-Qods Branch, Islamic Azad University, Tehran, Iran, Email Shahsavani.|@gmail.com

Received: December 22, 2017 | Published: March 16, 2018

Keywords: cross-linked, food value, rye noodles, trans-glutaminase

\section{Introduction}

The rye is a plant of the family of grasses. Rye is the second most common European cereal in Europe, which is used largely in the north, center, and east of parts of Europe in bread making, but in recent decades its cultivation has declined. Rye generally contains high levels of fiber in the diet, vitamins, minerals and essential amino acids, as well as good sources of magnesium, selenium, manganese, phosphorus and vitamins of group B, including folic acid. In addition, it is a great source of dissolved and insoluble fibers. . Noodles are one of the most important and best foods for the people of the world, especially Asian countries. Today's busy life has deprived people of healthy eating, today's mothers and wives have little time to cook traditional foods. On the other hand, eating prepared foods and shopping from fast food restaurants has caused people to have problems with their own health and their families. The transglutaminase enzyme naturally exists in most animal tissues and body fluids. This enzyme only promotes proteins by accelerating the covalent bond between the carboxylic amide group of the lateral chain of the glutamate root and the lysine side chain amino acid group. ${ }^{1} \mathrm{Wu}$ and Cork used the enzyme in the White Noodle Building in $2005,{ }^{2}$ and stated that the samples had better rheological properties than the enzyme-free control sample, slightly less desirable color, less solids lost to cooking water. In 2016, Comino et al. ${ }^{3}$ reported that adding some rye flour to wheat flour could produce more water-absorbing paste that also preserves its novelty from the dough. Survjannametakol et $\mathrm{al}^{4}{ }^{4}$ in 2017 reported that rye flour retains a higher nutrient content than wheat flour because it is difficult to separate bran and juniper from it. Sandberg et al. ${ }^{5}$ In 2017, reported that the addition of some rye flour to wheat flour could result in a more water-absorbing paste that will keep its final product fresh longer. According to Boxa et al. ${ }^{6}$ in 2015, the presence of pentosane, especially soluble pentosane in water and protein, has a major impact on the absorption of rye flour in bread. In this research, the use of rye flour to increase the nutritional value of noodle cereal products is performed for the first time in a laboratory system. The purpose of this research is to produce a product with high potential for food and lower calories and better quality.

\section{Methodology}

In this study, the transglutaminase enzyme was produced by German Ajinomoto Co., Inc. (Tokyo, Japan). Rye flour was bought from the Maltese Shop and wheat flour was obtained from local market.

\section{Method of preparing}

Wheat flour, salt, barley, trans-glutaminase and rye flour were preprepared. Wheat flour was weighed and kept at ambient temperature for some times. The level of enzyme transglutaminase was fixed at $1 \%$ (by weight) and rye flour in $0,20,40$ and $60 \%$ (by weight) in formulation. Using a medium-speed mixer, all the ingredients were mixed together uniformly and the dough was homogeneous. Increasing the amount of rye flour in the formulation of the time required for mixing was higher. The resulting dough was cut to a uniform size by a manual cutting machine, placed in a plastic bag and placed in the refrigerator for 24 hours. In all tests, the control sample (containing flour and enzyme transglutaminase, non-rye flour) with code B and specimens containing 20,40 and $60 \%$ rye flour were identified by B1, $\mathrm{B} 2, \mathrm{~B} 3$, respectively.

\section{Proximate analysis}

Each noodle sample was evaluated for moisture, crude protein, crude fat, crude fiber, and ash contents according to (AOAC 2003) the Official methods of analysis of the Association of Official Analytical Chemists. $^{7}$ All measurements were expressed as on a dry weight basis and performed in triplicate.

\section{Cooking properties}

Cooking yield and cooking loss of the noodles were determined as described by Akanbi \& Foo et al. ${ }^{8,9}$ precisely $30 \mathrm{~g}$ of the noodles 
were added to about $300 \mathrm{ml}$ boiling water for $10 \mathrm{~min}$. The cooked noodles were drained and rinsed for $5 \mathrm{~min}$ and then waited. Cooking loss was determined by evaporating to dryness the combined cooking and rinse water in a pre-weighed glass beaker in an oven at $110^{\circ} \mathrm{C}$ for $24 \mathrm{~h}$. The residue was weighed after cooling in a desiccator and reported as cooking loss.

Cooking yield $(\mathrm{g})$ = weight of noodles after cooking $(\mathrm{g})$ - weight of noodles before cooking $(\mathrm{g})(1)$

$$
\text { Cooking loss }(\%)=\frac{\text { remaining solid weight } \times 100}{\text { weight of noodles before cooking }}
$$

\section{Cross-linked rye noodle firmness}

The firmness of cooked noodles was measured by using a Texture Analyzer, TA. XT2 Plus (Stable Micro Systems, Surrey, England) with a $5 \mathrm{~kg}$ load cell attached with a $1 \mathrm{~mm}$ flat Perspex knife blade according to the AACC method (American Association of Cereal Chemists). The used settings were: Mode: Measure force in compression, Option: Return to start, pre-Test Speed: $4.0 \mathrm{~mm} / \mathrm{s}$, Test Speed: $1.0 \mathrm{~mm} / \mathrm{s}$, Post-Test Speed: $1.0 \mathrm{~mm} / \mathrm{s}$, strain: $70 \%$, Trigger type: Auto. The cooked noodles were cut in small pieces in length and five noodles strands were placed side-by-side, straight and flat and were place at the center under the compression blade. The firmness value was taken from the peak of a force-time graph.

\section{Tensile test for cross-linked rye noodle}

Tensile strength of noodle strands was evaluated by using Texture analyzer, TAXT model (Stable Micro Systems Surrey, UK) fitted with a $5 \mathrm{~kg}$ load cell. Ring calibration was performed prior to measurement. The distance of the probe move apart was set at $15 \mathrm{~mm}$. The setting used to be: Mode: Measure force in tension; Option: Return to start; Pre-test speed: $3.0 \mathrm{~mm} / \mathrm{s}$; Test speed: $3.0 \mathrm{~mm} / \mathrm{s}$; Post-test speed: 5.0 $\mathrm{mm} / \mathrm{s}$; Distance: $100 \mathrm{~mm}$. The cooked noodles strands were cut into $20 \mathrm{~mm}$ long. The width and thickness of the strand were determined at three different locations using a manual micrometer (Dial Thickness Gauge Mitutoyo MI 7305, Japan). The tensile strength was calculated as:

$$
a=\frac{\mathrm{F}}{\mathrm{A}}(3)
$$

where a is the tensile strength $(\mathrm{Pa}), \mathrm{F}$ is the peak force $(\mathrm{N})$ and $\mathrm{A}$ is the cross-sectional area of the noodle strand $\left(\mathrm{m}^{2}\right){ }^{9}$

\section{Statistical analysis}

All analyses in this study were run in triplicate and the data were analyzed statistically using SPSS version 19.0. Results were analyzed by comparing the means using one-way analysis of variance (ANOVA), and Duncan`s multiple range test was used to determine significant difference $(\mathrm{P}<0.05)$ among the different formulations.

\section{Results}

Proximate properties of noodles are shown in Table 1. The proximate properties of all noodle samples varied significantly $(p<0.05)$ different. The mean protein and fat contents of cross-linked rye noodles, ranged from 13.4 (B) to 15.18 (B2) and 0.98 (B) to 1 (B2), respectively. This trend portends that the higher the percentage rye flours in the blend, the higher the protein content. The ash contents ranged from 0.71 (B) to 3.4 (B2) which might be due to the fact that rye flour are high in ash. As shown in Table 1, there is a significant difference in terms of moisture content, fiber, ash and protein content of the product. The results of this table indicated that the amount of moisture with the increase in rye flour and the reduction of wheat flour content in the formulation are significantly reduced while increasing the amount of minerals but the level of protein increased. It may be, due to the rye flour has more minerals and protein than wheat flour. Therefore, by increasing the amount of rye in the formula, the amount of wheat flour decreased so, fiber, protein and minerals increased. Studies have shown that crude fiber is best obtained from foods than supplement and can reduce symptoms of chronic constipation; heart diseases associated with high cholesterol, diverticular disease and reduce the risk of colon cancer. Hence, B2 noodles could be acceptable in places where fiber diets and lower fatty foods are desired. ${ }^{10,11}$

Table I Proximate composition of cross-linked rye noodle (by weight)

\begin{tabular}{llllll}
\hline Sample & Fat \% & Protein \% & Fiber \% & Moisture \% & Ash \% \\
\hline Flour & $0.98 \pm 0.2^{\mathrm{a}}$ & $13.42 \pm 0.3^{\mathrm{e}}$ & $1.16 \pm 0.3^{\mathrm{e}}$ & $12 \pm 0.5^{\mathrm{a}}$ & $0.67 \pm 0.4^{\mathrm{e}}$ \\
Rye & $0.78 \pm 0.1^{\mathrm{b}}$ & $14.5 \pm 0.1^{\mathrm{d}}$ & $2.80 \pm 0.1^{\mathrm{d}}$ & $9.44 \pm 0.3^{\mathrm{b}}$ & $1.75 \pm 0.4^{\mathrm{d}}$ \\
B & $0.98 \pm 0.4^{\mathrm{a}}$ & $13.40 \pm 0.7^{\mathrm{e}}$ & $1.18 \pm 0.2^{\mathrm{e}}$ & $11.93 \pm 0.3^{\mathrm{a}}$ & $0.71 \pm 0.2^{\mathrm{e}}$ \\
BI & $1.00 \pm 0.9^{\mathrm{a}}$ & $14.95 \pm 0.2^{\mathrm{c}}$ & $2.22 \pm 0.1^{\mathrm{c}}$ & $8.6 \pm 0.4^{\mathrm{c}}$ & $2.2 \pm 0.0^{\mathrm{c}}$ \\
B2 & $1.1 \pm 0.8^{\mathrm{a}}$ & $15.05 \pm 0.5^{\mathrm{b}}$ & $3.28 \pm 0.3^{\mathrm{b}}$ & $7.1 \pm 0.5^{\mathrm{d}}$ & $2.7 \pm 0.1^{\mathrm{b}}$ \\
B3 & $1.0 \pm 0.7^{\mathrm{a}}$ & $15.18 \pm 0.6^{\mathrm{a}}$ & $3.40 \pm 0.00^{\mathrm{a}}$ & $6.0 \pm 0.3^{\mathrm{e}}$ & $3.4 \pm 0.01^{\mathrm{a}}$ \\
\hline
\end{tabular}

Means in the same column with different superscripts are different $(p<0.05)$.

Cooking quality of noodles could be defined by measuring the cooking yield. Cooking lost is the most important parameter for cooking quality of noodles ${ }^{9,12}$ Research has shown that ash increasing is a sign of increasing fiber in the food. The amount of ash and higher fiber, indicating more fibrous particles in the product, are observed in samples containing rye flour, which can lead to decrease in moisture content, increase in water absorption and, consequently, increase in swelling index. Swelling is a sign of water absorption by starch granules, which increases by increasing the amount of starch in the product (Figure 1).

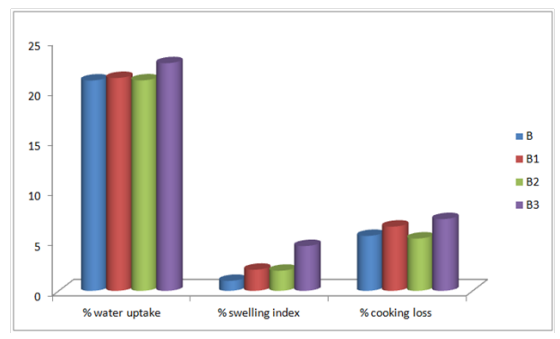

Figure I Cooking properties of cross-linked rye noodle.

But cooking loss of cross-linked rye noodles decreased by increasing level of rye flour up to level of $40 \%$ (B2). The highest cooking lost was found in sample B3, which made by $60 \%$ rye flour. The degree of cooking lost is depended on starch gelatinization ${ }^{13,14}$ and cooking lost in this study can better controlled by using transglutaminase as cross-like agent at B2.

The highest water uptake was due to sample B3 and the lowest was for sample B2 Figure 1 shows that two samples (B1 and B) do not differ significantly in terms of water uptake, so according to 
the results, the addition of $20 \%$ rye flour to the formulation did not have a significant effect on water absorption after cooking, by using transglutaminase agent the amount of water uptake can be controlled in sample B3, and the resulting evidence is similar to the reports obtained by Huang \& Lai, ${ }^{15}$ Comino et al. ${ }^{3}$ Wang et al. ${ }^{16}$ Anderson et al. ${ }^{17}$ Also, high dietary fiber in rye flour, during noodles cooking led to the absorption of more water in to the gelatinized matrix structures of noodles and could result in higher cooking lost and water uptakes in this study (Figure 1). The research indicated that due to the increased use of rye flour in the preparation of the noodle, the amount of cooking lost increased, and it can prioritize the stability of the control sample compared to other rye flour samples (Figure 1). As the amount of cooking loss increases, it indicates an increase in the amount of amylose leaching into the cooking water and an increase in the degree of gelatinization of the starch in the product, due to the use of the microbial transglutaminase enzyme, amylose leaching amounted to a significant reduction in cooking water and the amount of gum was controlled by increasing the percentage of rye flour and reducing the amount of wheat flour. This can be attributed to the ability of transglutaminase to improve cross-linkages between proteins and enhance protein networks.

Based on the results, there was a significant difference in water absorption between samples at $40 \%$ level. The results indicate that by increasing the percentage of rye flour in the product, the amount of gluten increase and naturally more water is needed to make the dough. Absolute complete hydration of flour particles in the dough as well as the presence of starch in rye flour is the cause of loosening of the dough before baking, and finally a product with porous structure is produced and this change in structure increases the water holding capacity and swelling of the nodules. The enzyme transglutaminase catalyze the acetyl acetylation reaction between the gamma carboxyamide band of peptide glutamine and the first type amines. So this enzyme can make covalent transitions between proteins and enhance the protein network and the strength of the product's structure. Therefore, the addition of rye flour to the noodle formulation, due to the increase in per capita consumption of this product for enrichment, can be a novel and novel ground break Holt et al. In addition, further research is needed to improve the properties of baking. Cooking loss is one of the important attributes in determining the properties of a noodle and expresses its quality. The main component of the effective starch in cooking loss is amylose, and amylose is a bonding agent in baking paste products. ${ }^{18}$ The results of Huang and Lai's reports, ${ }^{15}$ Wang et al. ${ }^{16}$ Joo et al. ${ }^{19}$ are evidence of confirmation of the results obtained in this study. Tensile strength and firmness are important parameters to define the quality of the noodles. ${ }^{20}$ Cooked noodles should have elasticity and firmness. Wheat flour protein content, can effect on the texture on noodles. ${ }^{21}$ The addition of rye flour decreased the 900ikfirmness and increased the tensile strength of the noodles sample that may be due to the protein properties of rye. As the amount of rye flour addition was increased, the viscoelastic improved at level of $40 \%$ rye flour (B2). Also, this led to more activity of transglutaminase and decreased in firmness but tensile strength increased respectively up to $40 \%$ (Figure 2 ).

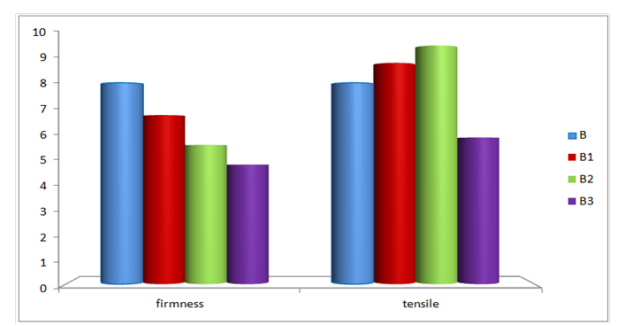

Figure 2 Texture characteristics of cross-linked rye noodle.

\section{Acknowledgment}

Author declares no acknowledgment.

\section{Conflict of interest}

Author declares no conflict of interest.

\section{References}

1. Kotova YN, Abaeva AA, Kolyadko $\mathrm{VN}$, et al. The role of transglutaminases in the regulation of phosphatidylserine-positive platelet formation. Biochemistry (Moscow) Supplement Series A: Membrane and Cell Biology. 2015;9(4):229-235.

2. Wu J, Corke H. Quality of dried white salted noodles affected by microbial transglutaminase. Journal of the Science of Food and Agriculture. 2005;85(15):2587-2594.

3. Comino P, Collins H, Lahnstein J, et al. Effects of diverse food processing conditions on the structure and solubility of wheat, barley and rye endosperm dietary fibre. Journal of Food Engineering. 2016;169:228-237.

4. Surojanametakul V, Srikulnath S, Chamnansin P, et al. Survey of Thai Commercial Food Products That Have Been Reported to Contain No Wheat, Rye, Barley, or Gluten According to Their Labels. J AOAC Int. 2017;100(1):126-132.

5. Sandberg JC, Björck IM, Nilsson AC. Effects of whole grain rye, with and without resistant starch type 2 supplementation, on glucose tolerance, gut hormones, inflammation and appetite regulation in an 11-14.5 hour perspective; a randomized controlled study in healthy subjects. Nutrition Journal. 2017;16(1):25.

6. Buksa K, Nowotna A, Ziobro R, et al. Rye flour enriched with arabinoxylans in rye bread making. Food Sci Technol Int. 2015;21(1):4554.

7. Approved Methods of the American Association of Cereal Chemists. MN, USA; 2000.

8. Akanbi TO, Nazamid S, Adebowale AA, et al. Breadfruit starchwheat flour noodles: preparation, proximate compositions and culinary properties. International Food Research Journal. 2011;18:1283-1287.

9. Foo W, Yew $\mathrm{H}$, Liong $\mathrm{M}$, et al. Influence of formulations on textural, mechanical and structural breakdown properties of cooked yellow alkaline noodles. International Food Research Journal. 2011;18(4):1295-1301.

10. Kritchevsky D, Bonfield CT. Dietary fiber in health and disease. Springer Science \& Business Media. 2012. 427 p.

11. Narita S, Inoue M, Saito E, et al. Dietary fiber intake and risk of breast cancer defined by estrogen and progesterone receptor status: the Japan Public Health Center-based Prospective Study. Cancer Causes Control. 2017;28(6):569-578.

12. Li J, Vasanthan T. Hypochlorite oxidation of field pea starch and its suitability for noodle making using an extrusion cooker. Food Research International. 2003;36(4):381-386.

13. Liu H, Yu L, Dean K, et al. Starch gelatinization under pressure studied by high pressure DSC. Carbohydrate polymers. 2009;75(3):395-400.

14. Sung WC, Stone M. Microstructural studies of pasta and starch pasta. $J$ Mar Sci Technol. 2005;13(2):83-88.

15. Huang YC, Lai HM. Noodle quality affected by different cereal starches. Journal of Food Engineering. 2010;97(2):135-143.

16. Wang M, Chen C, Sun G, et al. Effects of curdlan on the color, syneresis, cooking qualities, and textural properties of potato starch noodles. Starch-Stärke. 2010;62(8):429-434.

17. Andersson R, Fransson G, Tietjen M, et al. Content and molecular- 
weight distribution of dietary fiber components in whole-grain rye flour and bread. J Agric Food Chem. 2009;57(5):2004-2008.

18. Chang HC, Wu LC. Texture and quality properties of Chinese fresh egg noodles formulated with green seaweed (Monostroma nitidum) powder. J Food Sci. 2008;73(8):S398-S404.

19. Joo SI, Kim JE, Lee SP. Physicochemical properties of wholesoybean curd prepared by microbial transglutaminase. Food Sci Biotechnol. 2011;20:437-444
20. Han HM, Cho JH, Koh BK. Processing properties of Korean rice varieties in relation to rice noodle quality. Food Science and Biotechnology. 2011;20(5):1277-1282.

21. Yeoh SY, Alkarkhi AFM, Ramli SB, et al. Effect of cooking on physical and sensory properties of fresh yellow alkaline noodles prepared by partial substitution of wheat flour with soy protein isolate and treated with cross-linking agents. Int J Food Sci Nutr. 2011;62(4):410-417. 